\title{
A PERSPECTIVA DO MEIO AMBIENTE DO TRABALHO E AS ALTERAÇÕES LEGISLATIVAS A PARTIR DA LEI 13.467/2017
}

\author{
Marcelo Santoro Drummond* \\ Eduardo Augusto Gonçalves Dahas ${ }^{\dagger}$
}

\section{RESUMO}

$\mathrm{O}$ artigo reflete o panorama atual justrabalhista enfocando o meio ambiente do trabalho e alterações legislativas que se iniciaram com a denominada Reforma Trabalhista (Lei 13.467/2017). Serão analisados os efeitos provocados pela referida norma, bem como pela medida provisória n. ${ }^{\circ}$ 881, aprovada em agosto de 2019, além da integração das aludidas normas, suas motivações e perspectivas. Apontará como resultado a precarização das relações trabalhistas, proporcionando a elevação da submissão do empregado ao empregador, além do engessamento da Justiça do Trabalho em virtude das citadas alterações. Será utilizada a abordagem qualitativa, o método hipotético-dedutivo, com análise legislativa e doutrinária.

PALAVRAS CHAVE: Reforma Trabalhista; meio ambiente do trabalho; precarização; retrocesso social, Consolidação das Leis do Trabalho.

\section{THE WORK ENVIRONMENT PERSPECTIVE AND LEGISLTATIVE CHANGES FROM LAW 13.467/2017}

\begin{abstract}
The article reflects the current labor law panorama focusing on the work environment and legislative changes that began with the so-called Labor Reform (Law 13.467 / 2017). The effects of this standard, as well as the provisional measure 881, approved in August 2019, will be analyzed, as well as the integration of these standards, their motivations and perspectives. As a result, it will point out the precariousness of the labor relations, providing the increase of the submission of the employee to the employer, besides the stagnation of the Labor Justice due to the mentioned alterations. The qualitative approach will be used, the hypothetical-deductive method, with legislative and doctrinal analysis.
\end{abstract}

KEY WORDS: Labor reform; work environment; precariousness; social regression, Consolidation of Labor Laws

\section{INTRODUÇÃO}

\footnotetext{
* Mestre e doutorando em Direito. Professor de Direito e Processo do Trabalho da Escola Superior Dom Helder Câmara. Email: djowe@uol.com.br

${ }^{\dagger}$ Mestre e Doutorando em Direito. Professor de Direito do Trabalho dos Cursos de Graduação e Pós Graduação da Faculdade Pitágoras de Minas Gerais. Email: edahas@agq.adv.br
} 
O meio empresarial, bem como os representantes políticos a ele vinculado, expressaram, ao longo do fim da última década e durante toda a presente, notória insatisfação acerca do arcabouço normativo justrabalhista vigente até então, deduzindo inúmeras críticas não somente ao conteúdo legislativo construído ao longo de inúmeras décadas, bem como se insurgido contra a postura de grande parte do judiciário trabalhista, tendo em vista seus posicionamentos, bem como sua postura pró ativa na interpretação da norma e solução dos conflitos, por intermédio da edição de inúmeras súmulas, orientações jurisprudenciais e precedentes.

Sustentaram referidos segmentos da sociedade que a crise econômica vigente, bem como a legislação também em vigor, teriam o condão de inibir por completo o pleno exercício da atividade empresarial, comprometendo, inclusive, princípios inarredáveis extraídos da Constituição da República de 1988, como aquele estampado no seu artigo 170, alusivo à função social da empresa.

Como reflexo da reação do empresariado e da classe política a ele atrelada, que exerceram em conjunto pressão notória sobre os entes governamentais, inaugurou-se, a partir de 2017, com a edição e entrada em vigor da Lei n. ${ }^{\circ} 13.467$ de 2019, conhecida em todos os meios como Reforma Trabalhista, um novo momento do desenvolvimento do Direito e do Processo do Trabalho no país, que passa também pela aprovação pelo Congresso Nacional da Medida Provisória n. ${ }^{\circ} 881$ de 2019, ocorrida em agosto do referido ano, sob o argumento de se conferir maior desburocratização e dinamismo à relação de emprego.

A partir de tal panorama, o objeto central do presente estudo é traçar um paralelo entre a evolução prestigiosa do Direito do Trabalho, que perdurou até meados da presente década, os efeitos de retração decorrentes das legislações que recentemente entraram em vigor (e que provavelmente deverão ter vigência por tempo prolongado) e sua influência perante o meio ambiente laboral.

Buscar-se-á situar o meio ambiente do trabalho e sua perspectiva futura em virtude das tendências legislativas que surgiram nos últimos anos e que ocasionarão efeitos concretos e profundos nos contratos de trabalho.

Tendo em vista o recente panorama aqui delineado, justifica-se a presente pesquisa em virtude do estado de risco pelos quais passam os institutos justrabalhistas, seja no tocante ao direito material, seja em sua esfera processual. 
A análise que se presta a desenvolver a partir do artigo em questão buscará sopesar referidos e recentes preceitos legais contrapondo-os com todo o sistema legal vigente no país.

$\mathrm{O}$ enfoque do tema derivará também da afirmação e salvaguarda do princípio da Dignidade da Pessoa Humana, na medida em que a Constituição da República assegura como direito fundamental, ou seja, intangível, o acesso ao ser homem trabalhador a condições justas e dignas de trabalho, sem qualquer exposição a situações desumanas, estafantes ou que venham a diminuir a sua condição como ser humano.

Será também demonstrada a existência de uma nova tendência atinente às relações juslaborais, no sentido de flexibilização e tangibilidade do denominado meio ambiente do trabalho. O questionamento que se faz seria: estaria se inaugurando uma nova era de desconstrução do direito fundamental a um meio ambiente do trabalho digno, saudável e equilibrado?

O presente estudo também se justifica a partir de uma necessidade premente de se erigir um pensamento, bem como atitudes concretas, no sentido de se retomar o caminho da proteção social, prestigiando o meio ambiente do trabalho, buscando frear a tendência de precarização surgida nos últimos tempos.

Para o alcance dos objetivos propostos ao presente estudo, será utilizado como elemento de pesquisa a abordagem qualitativa, a partir da explanação da interação do meio ambiente do trabalho a todo um conteúdo sistemático sacramentado pela Constituição da República de 1988, alicerçado por dispositivos históricos contidos na CLT, bem como o confronto com a legislação recém implantada.

Será utilizado também o método hipotético-dedutivo buscando uma análise da inter

relação das normas, princípios e mecanismos que afirmar a proteção ao trabalhador hipossuficiente e a nova e precarizante legislação, tendente ao retrocesso social.

\section{A CONSTRUÇÃO HISTÓRICA DE UM SISTEMA NORMATIVO PROTETIVO AO TRABALHADOR BRASILEIRO - A PROTEÇÃO AO MEIO AMBIENTE DO TRABALHO COMO UM DIREITO FUNDAMENTAL E HUMAO ALBERGADO PELA CONSTITUIÇÃO DE 1988}


O Direito do Trabalho, como ramo do direito em pleno desenvolvimento, sendo objeto de inúmeras alterações ao longo dos tempos, especialmente nos últimos oitenta anos, se caracterizou como um notório instrumento de elevação da condição social humana.

A construção legislativa no Brasil, bem como a organização judiciária trabalhista, se notabilizaram como elementos de contrapeso da vontade e submissão empresarial sobre a classe trabalhadora, no sentido de propor normas de equilíbrio, bem como em efetiva-las, objetivando a isonomia entre os entes contratantes e, em um segundo e eventual momento, entre os entes litigantes perante a Justiça do Trabalho.

Ainda que alvejada por momentos sintomáticos de flexibilização, ao longo dos anos, dos quais se aponta como exemplo a criação do Fundo de Garantia por Tempo de Serviço- FGTS, em 1966, a "Nova Lei do Contrato a Termo", de 1998, dentre outras manifestações, tanto o direito quanto o processo do trabalho foram objeto de afirmação e prestígio ao longo dos anos, cumprindo relevante papel no desenvolvimento humano, servindo como um dos poucos instrumentos do país na consecução da elevação do patamar de civilização do ser humano e de seu crescimento profissional e pessoal.

A relevância do trabalho e sua vinculação com o sustentáculo da dignidade humana é assim transcrita e bem exposta nas palavras de Bruna Pinotti Garcia e Rafael de Lazari, ao tratarem da evolução histórica dos direitos humanos:

“O trabalho decente, conceito formalizado pela OIT em 1999, sintetiza a sua missão histórica de promover oportunidades para que homens e mulheres possam ter um trabalho produtivo e de qualidade, em condições de liberdade, equidade, segurança e dignidade humanas, sendo considerado condição fundamental para a superação da pobreza, a redução das desigualdades sociais, a garantia da governabilidade democrática e o desenvolvimento sustentável ” (Garcia, Lazari, 2014, p. 125)

Portanto, o Direito do Trabalho assume relevante papel na consecução dos direitos humanos, na medida em que seu instrumento essencial é a valorização e efetivação de mecanismos que garantam o trabalho digno, permitindo ao homem a elevação de sua condição 
social, intelectual e econômica, passando a ser um elemento operário da construção de uma sociedade digna e equilibrada.

E o trabalho digno repercute na construção de ferramentas e ambientes adequados para seu desenvolvimento e afirmação. Daí a plena necessidade de se vislumbrar um meio ambiente digno de labor, que permite ao trabalhador o exercício digno e equilibrado de suas atividades, sem que lhe seja causado qualquer transtorno ou malefício, especialmente no tocante à saúde física e mental, mas também que lhe permita sopesar e usufruir de seus compromissos e anseios pessoais, referentes à sua inserção perante a sociedade que o cerca.

A relevância do meio ambiente do trabalho é exposta pelo magistrado e jurista Sebastião Geraldo de Oliveira, em notória obra acerca do meio ambiente do trabalho, com enfoque na saúde e segurança do trabalhador. De tal modo, assim dispõe o autor no tocante aos amplos fatores inerentes ao bem-estar do empregado, ou seja, que norteiam o meio ambiente laboral:

"No enfoque global verificam-se todos os fatores que interferem no bem-estar do empregado. Não só o posto de trabalho, mas tudo que está em volta, o ambiente do trabalho. E não só o ambiente físico, mas todo o complexo de relações humanas na empresa, a forma de organização do trabalho, sua duração, os ritmos, os turnos, os critérios de remuneração, as possibilidades de progresso, o "clima” organizacional, a satisfação dos trabalhadores, etc.” (Oliveira, 2004, p.82)

Corroborando aludido entendimento, Rubia Zanotelli Alvarenga e Flávia Moreira Marchiori afirmam a imperiosa necessidade de submissão do empregado a um meio ambiente justo e equilibrado, para que execute um labor saudável, tendo como efeito precípuo de sua relação de emprego uma plena qualidade de vida, preservando sua saúde física e mental. De tal modo, veja-se:

"O direito fundamental à saúde mental está, assim, diretamente relacionado à qualidade de vida dos trabalhadores no ambiente de trabalho e visa a promover a incolumidade psicológica e física destes durante o desenvolvimento de sua atividade profissional, de modo que o trabalho possa ser desenvolvido de forma saudável e equilibrado, já que sem saúde não há vida digna e sem meio ambiente equilibrado não há saúde.” (Alvarenga, Marchiori, 2013, p. 171) 
E complementam, de forma absolutamente pertinente, as referidas autoras acima citadas:

"Em todo este contexto insofismável de defesa ao direito fundamental à saúde, em especial à saúde mental, o trabalhador encontra guarida para a tutela de sua vida e dos direitos da personalidade, nestes incluído o direito à integridade psicofísica. “

Para melhor qualidade de vida, o trabalhador, assim, necessita conviver em um meio ambiente de trabalho saudável e equilibrado, a fim de que o exercício do trabalho não prejudique à sua saúde mental e, por consequência, à sua identidade física. Os danos de ordem psíquica e física são distintos entre si e podem atuar tanto de forma isolada quanto cumulativamente".

Por conseguinte, presume-se o direito à proteção ao meio ambiente do trabalho como um direito fundamental, vinculado diretamente aos direitos humanos, ante a afirmação do princípio da dignidade da pessoa humana.

E referido direito alcança nítida proteção constitucional, conforme se depreende do disposto no artigo $1 .^{\circ}$ da Constituição da República de 1988, afirmando os direitos à cidadania, dignidade da pessoa humana, valores sociais do trabalho, respectivamente referidos em seus incisos II, III e IV.

Verifica-se também a referência expressa por meio do rol dos direitos sociais dos trabalhadores, contidos no artigo $7 .^{\circ}$, exemplificando o disposto no inciso XXII, da Constituição de 1988, que prevê o direito à "redução dos riscos inerentes ao trabalho, por meios de normas de saúde, higiene e segurança”.

Vislumbra-se também no título VIII da Constituição brasileira, alusivo à ordem social e os aspectos inerentes aos direitos à saúde, de modo geral, o disposto referido no artigo 200, em seu inciso VIII, que dispõe sobre o dever do sistema de saúde em "colaborar na proteção do meio ambiente, nele compreendido o do trabalho".

Corroborando o raciocínio acima, Valdete Souto Severo assim dispõe no tocante à salvaguarda do meio ambiente laboral: 
"O Direito do Trabalho se inscreve como direito humano que, em âmbito nacional, é classificado como direito fundamental de segunda geração. Está diretamente relacionado à saúde e à existência digna. Tem, pois, dimensão individual e social que não se dissociam. Bem, por isso, cada vez tem sido mais recorrente a compreensão de que o Direito do Trabalho deve ser examinado de forma sistêmica, a partir de sua percepção como um meio ambiente, na diç̧ão expressa do art. 200 da Constituição.

E complementa a referida autora, com extrema pertinência e relevância:

O direito de proteção ao meio ambiente, cujo caráter de direito humano fundamental não se discute, constitui matéria que também entrelaça direito privado e direito público e interage com todos os ramos do direito. Os riscos de que novos equilíbrios não deixem espaço para a raça humana, faz com que a humanidade sinta necessidade de regular suas atividades em conformidade com essa ameaça” (Severo, 2015, p. 63)

Assim, inequívoca a proteção intangível a partir da Constituição de 1988 ao interesse maior do ser humano trabalhador, permitindo-lhe usufruir de um meio ambiente laboral saudável, abrangendo todos os aspectos que refletem no oferecimento e manutenção de sua saúde plena, a partir dos aspectos inerentes ao trabalho.

Percebe-se, portanto, que a Constituição Federal de 1988 cria todo um sistema lógico normativo de proteção ao meio ambiente de trabalho saudável e justo, exigindo sua oferta ao trabalhador, pelo seu tomador de serviço, bem como também determinando a observância de comandos que visem à manutenção deste ambiente saudável, que deverá também servir de instrumento para a inserção do homem trabalhador a uma melhor condição devida sob o aspecto social, econômico e cultural.

O meio ambiente de trabalho saudável, justo e equilibrado surge como verdadeiro alicerce ao equilíbrio das relações contratuais de emprego, servindo como base inquestionável para a construção de uma sociedade justa, a partir dos valores do trabalho humano.

Presume-se, pois, que o arcabouço legislativo erigido a partir da Constituição de 1988 eleva todos os atributos e características alusivas ao meio ambiente laboral, dentre elas a preservação da saúde e condição física e mental equilibrada do empregado, tendo como premissa condições equilibradas de execução do contrato, a um direito fundamental reconhecido como de 
terceira geração. De tal modo, dispõe o jurista e magistrado trabalhista Marcelo Rodrigues Prata:

"Por outro lado, saliente-se que o meio ambiente é um bem da vida, cuja proteção efetiva interessa não só aos indivíduos ou à comunidade imediatamente afetados pela lesão ao sistema ecológico, mas, igualmente, aos povos de vários países e até mesmo ao gênero humano universalmente considerado, o que realça a inserção do meio ambiente do trabalho no âmbito dos direitos de terceira dimensão. Por outras palavras, o meio ambiente do trabalho de sadia qualidade de vida é um bem abstrato que possui um valor intrínseco." (Prata, 2013, p. 184-185)

E referida proteção deveria alcançar todos os aspectos inerentes ao contrato de trabalho, como o estabelecimento de jornadas de trabalho justas, equilibradas e não estafantes, que permitam a execução eficiente e prazerosa do contrato de trabalho, não servindo também como instrumento de alijamento do empregado de seus direitos básicos como ser humano.

Assim, não poderá o trabalho inviabilizar sua inserção na sociedade, seu convívio familiar e o alcance de objetivos pessoais alheios à execução do contrato de trabalho, que não poderá se ocupar de tempo excessivo do trabalhador, sob pena de se constituir em elemento escravizante e maléfico, gerando consequências nocivas à vida do homem, no que toca à sua condição de ser humano com direito ao lazer, convívio pleno familiar, dentre outros fatores relevantes inerentes à vida humana.

\section{A PRECARIZAÇÃO DO MEIO AMBIENTE DO TRABALHO - ROMPIMENTO COM A TENDÊNCIA HISTÓRICA PROTETIVA E INAUGURAÇÃO DE UMA NOVA ERA DE “ SUBDIREITOS” - O ADVENTO DA LEI 13.467 DE 2017 E DA MEDIDA PROVISÓRIA N. ${ }^{\circ} 881$ DE 2019}

$\mathrm{Na}$ primeira parte do presente estudo, demonstrou-se a existência de toda uma construção legislativa (que se tornou efetiva ao longo dos anos, muito por força da interveniência da Justiça do Trabalho na consecução da efetivação dos direitos trabalhistas), no sentido de conferir notória proteção ao meio ambiente do trabalho e ao trabalhador nele inserido.

Demonstrou-se a validade de inúmeros preceitos de ordem constitucional que elevam o 
direito a um meio ambiente laboral justo, equilibrado e saudável como um direito fundamental, neste caso, de terceira geração.

E como tal, aludidas normas deveriam ser dotadas de notória inflexibilidade, na medida em que se constituem em direito absoluto, homogêneo e inerente a qualquer cidadão trabalhador.

Referida construção jurídico-normativa existente e incidente sobre as relações jurídicas de emprego não admitiria (em tese), qualquer hipótese de retração, especialmente derivada da ordem jurídica infraconstitucional.

Todavia, o contexto legislativo inerente ao Direito do Trabalho revela um panorama absolutamente diverso daquele legalmente constituído e determinado ao longo das décadas, iniciando em meados do século passado, caminhando até meados da presente década. Verificouse nos últimos anos, a partir de 2017, com a entrada em vigor da denominada "Reforma Trabalhista" (Lei de n. ${ }^{\circ}$ 13.467), a imposição a partir de uma lei ordinária, de inúmeros preceitos que destoam da realidade histórica experimentada nas últimas décadas, revelando um futuro incerto para as relações de emprego.

E nesse panorama de notórias incertezas, derivadas de não menos concretas precariedades contidas na aludida lei, o conceito, proteção e abrangência do meio ambiente do trabalho (assim definido de forma ampla) é posta em xeque, tendo em vista disposições sistematizadas propositalmente no sentido de precarizar as relações de trabalho, alcançando, por sua vez, o meio ambiente laboral.

Cumpre aqui apontar, como exemplo e reflexo dessa "onda" não protecionista e de precarização, a inserção do disposto nos artigos 611-A, da CLT, que assim dispõe em vários de seus incisos:

“Art. 611-A. A convenção coletiva e o acordo coletivo de trabalho têm prevalência sobre a lei quando, entre outros, dispuserem sobre: (Incluído pela Lei $n^{\circ}$ 13.467, de 2017)

I - pacto quanto à jornada de trabalho, observados os limites constitucionais; (Incluído pela Lei $n^{\circ} 13.467$, de 2017)

II - banco de horas anual; (Incluído pela Lei nº 13.467, de 2017) 
III - intervalo intrajornada, respeitado o limite mínimo de trinta minutos para jornadas superiores a seis horas; (Incluído pela Lei no 13.467 , de 2017)

(...)

VIII - teletrabalho, regime de sobreaviso, e trabalho intermitente; (Incluído pela Lei $\mathrm{n}^{\circ}$ 13.467, de 2017)

(..)

X - modalidade de registro de jornada de trabalho; (Incluído pela Lei no 13.467, de 2017)

(...)

XII - enquadramento do grau de insalubridade; (Incluído pela Lei $n^{\circ} 13.467$, de 2017)

XIII - prorrogação de jornada em ambientes insalubres, sem licença prévia das autoridades competentes do Ministério do Trabalho; (Incluído pela Lei $\mathrm{n}^{\circ}$ 13.467, de 2017)"

Partindo das alterações legais acima previstas, vislumbra-se a possibilidade de redução de intervalo para refeição e descanso de uma hora para apenas trinta minutos, a adoção de regimes de compensação prolongados, expondo o trabalhador a jornadas extraordinárias excessivas, flexibilização da proteção à saúde dos empregados, na medida em que os instrumentos coletivos podem dispor acerca da fixação de grau para o pagamento do adicional de insalubridade, além de poderem permitir a extensão da execução das atividades em ambientes insalubres.

Tais disposições mitigam sobremaneira o meio ambiente do trabalho, na medida em que permitem a sujeição do trabalhador a jornadas estafantes, sem a devida reposição das forças sob os aspectos físico e mental, a partir de períodos de descanso adequados.

Verifica-se a submissão a condições insalubres de labor com menos proteções legais e compensações financeiras.

Além das disposições aqui elencadas, que por si só já revelam a intenção do legislador em minimizar a proteção ao meio ambiente laboral, reduzindo sua importância e alcance, há que se apontar outros preceitos também inseridos no ordenamento jurídico pela denominada reforma 
trabalhista. Desta feita, veja-se abaixo a disposição acerca da possibilidade do fracionamento excessivo das férias:

“Art. 134 - As férias serão concedidas por ato do empregador, em um só período, nos 12 (doze) meses subseqüentes à data em que o empregado tiver adquirido o direito. (Redação dada pelo Decreto-lei no 1.535 , de 13.4.1977)

$\S 1$ o Desde que haja concordância do empregado, as férias poderão ser usufruídas em até três períodos, sendo que um deles não poderá ser inferior a quatorze dias corridos e os demais não poderão ser inferiores a cinco dias corridos, cada um. (Redação dada pela Lei $n^{\circ} 13.467$, de 2017)"

Portanto, verifica-se a possibilidade de se fracionar o gozo das férias anuais, que seriam hipoteticamente de 30 dias, em três períodos distintos, podendo ser um deles de cinco dias apenas.

Vê-se, por conseguinte, a notória inviabilidade de concessão do trabalhador de período adequado para a reposição de suas forças físicas e mentais, além de comprometer a saudável desvinculação ao trabalho, permitindo sua inserção na vida familiar, convívio social e dedicação a projetos de caráter pessoal.

Por fim, no que toca aos apontamentos dos preceitos derivados da Lei n. ${ }^{\circ} 13.467$ de 2017, urge também fazer referência ao que aponta o conteúdo no artigo 611-B, parágrafo único, da CLT, que revela preocupante "novidade" derivada de tal norma:

"Parágrafo único. Regras sobre duração do trabalho e intervalos não são consideradas como normas de saúde, higiene e segurança do trabalho para os fins do disposto neste artigo."

A partir do dispositivo em questão, revela-se flagrante intenção de mitigar o conceito e alcance do meio ambiente do trabalho, na medida em que se exclui de seu conceito e proteção quaisquer normas alusivas à duração da jornada e disposição acerca da fixação de intervalos.

Como já apontado, o direito a um meio ambiente equilibrado, saudável e justa resta totalmente mitigado, na medida em que os novos regramentos aqui citados permitem o pacto de jornadas de trabalho excessivas, redução de intervalos para refeição e descanso, diminuição dos períodos de descanso, não mais fazendo tais preceitos parte integrante do denominado meio 
ambiente do trabalho.

Daí a viabilidade de se deduzir, sem muito esforço interpretativo, a ocorrência de notórias inconstitucionalidades, na medida em que tais preceitos afrontam, de modo totalmente direto, o contido no artigo $7^{\circ}$, inciso XXII, da Constituição da República de 1988 , que versa acerca do direito aos riscos reduzidos no ambiente de trabalho, por intermédio de normas que assegurem a higiene, segurança e saúde do trabalhador, além de diversos outros dispositivos constitucionais também relevantes, como aqueles contidos no artigo $1 .^{\circ}$, inciso III, $5 .^{\circ}$, inciso III, artigo 200, inciso VIII.

E o panorama flexibilizatório, de mitigação e desprestígio ao meio ambiente do trabalho, afortunadamente, não se encerra tão somente com o advento da lei n. ${ }^{\circ} 13.467$ de 2017 , com vigência desde 11 de novembro de 2017. Recentemente, o Congresso Nacional chancelou a Medida Provisória de n. 811 de 2019, a denominada "MP da Liberdade Econômica", que aprofunda o retrocesso aqui descrito, com a inserção no ordenamento jurídico de novas normas trabalhista de cunho precarizador.

Dispõe o novo preceito, que quando da elaboração do presente artigo ainda dependia de chancela presidencial, acerca de supostas novas regras que serviriam para "desburocratizar" as relações de trabalho.

Cite-se, como exemplo exponencial das recentes alterações, aquelas inerentes à nova redação do artigo 74 da CLT e de seus parágrafos, que assim passariam a dispor, no caso de sanção presidencial do texto aprovado em definitivo no Senado Federal:

“Art. 74 - O horário do trabalho será anotado em registro de empregados.

$\S 1^{\circ}$ (Revogado).

$\S 2^{\circ}$ Para os estabelecimentos de mais de 20 (vinte) trabalhadores será obrigatória a anotação da hora de entrada e de saída, em registro manual, mecânico ou eletrônico, conforme instruções a serem expedidas pelo Ministério do Trabalho, devendo haver préassinalação do período de repouso.

$\S 3^{\circ} \mathrm{Se}$ o trabalho for executado fora do estabelecimento, o horário dos empregados constará do registro manual, mecânico ou eletrônico em seu poder, sem prejuízo do que 
dispõe o $§ 1^{\circ}$ deste artigo.

$\S 4^{\circ}$ Fica permitida a utilização de registro de ponto por exceção à jornada de trabalho, mediante acordo individual escrito, convenção coletiva ou acordo coletivo de trabalho."

Portanto, aludido preceito permite o afrouxamento da fixação de jornada de trabalho, eximindo o empregador de controlar formalmente a jornada por meio de instrumento próprio, para empreendimentos de até vinte empregados, substituindo a disposição anterior, que limitava a dez.

Ademais permite o registro de ponto por exceção, inclusive pela singela e precária (muitas vezes impositiva) prática, do acordo individual escrito, gerando a desnecessidade de anotação de jornada, exceto no caso de horas extras.

Referidos dispositivos precarizam o controle legal acerca dos limites de jornada, se constituindo em margem perigosa para fraudes e imposições de reais jornadas de trabalho excessivas, cuja prova ficaria a cargo do empregado, na medida em que não existiria controle de jornada, tornando desequilibrado o meio ambiente laboral.

Assim, referidos dispositivos se harmonizam (em notório retrocesso legal e social) com aquele já citado, oriundo da Lei 13.467, do artigo 611-B, parágrafo único, na medida em que o estabelecimento de normas alusivas a jornadas de trabalho não pertence ao escopo abarcado pelo meio ambiente laboral, contrariando inúmeros dispositivos constitucionais, na medida em que restará absolutamente afetada a saúde do trabalhador.

Presume-se, dessa maneira, que vivemos um momento de retrocesso socioambiental, no que toca ao aspecto laboral, na medida em o denominado meio ambiente do trabalho imaterial (estabelecimento de condições dignas, equilibradas e razoáveis e labor, como uma jornada de trabalho justa e coerente com a capacidade física e mental dos trabalhadores) restou desprestigiado pelos dispositivos contidos na Lei 13.467/2017 (Reforma Trabalhista), bem como pelo que também aponta os preceitos recém aprovados pela Medida Provisória de n. ${ }^{\circ} 881$ de 2019.

Referido contexto revela nítida mitigação de direitos conquistados ao longo dos anos, desconstruindo o pensamento e garantia acerca da necessidade protetiva ao meio ambiente do trabalho. A partir de tal realidade, Thiago Penido Martins e Virgínia Lara Bernardo Braz trazem à 
tona os efeitos derivados da referida "Reforma Trabalhista". Assim, veja-se:

"Nesse contexto, a legislação trabalhista passou por diversas mudanças, sendo parte delas encaradas por alguns segmentos da sociedade como redução/fragilização de direitos trabalhistas protegidos constitucionalmente, diminuindo o valor do trabalho na economia e na sociedade brasileiras. Para alguns segmentos sociais, a Lei Federal que trata da reforma não teria introduzido quase nenhum preceito favorável ao trabalhador, além de ter apresentado várias regras desfavoráveis, com objetivos antissociais e antihumanistas." (Martins, Braz, 2018, p. 109)

A saúde do trabalhador, por conseguinte, restará absolutamente afetada e agredida na medida em que se retira a proteção legal a uma jornada de trabalho equilibrada, como períodos de descanso que efetivamente tem o caráter de promover a necessária reposição das forças físicas e mentais.

\section{CONCLUSÃO}

O presente artigo buscou descrever a existência, a partir do advento da lei de n. ${ }^{\circ} 13.467$ de 2017 (Reforma Trabalhista), em vigor a partir de 11 de novembro do referido ano, de uma tendência e movimento de vulnerabilidade que atinge o meio ambiente do trabalho.

E referido contexto não se reflete em um ato isolado de precarização e desprestígio ao meio ambiente laboral, mas em uma nova era de retrocesso socioambiental, que atinge em cheio a seara justrabalhista.

E como apontado, referido momento de retração teve apenas seu início a partir da Reforma Trabalhista, já que outros dispositivos normativos surgiram a partir de então, como aquele decorrente da Medida Provisória de n. 881 de 2019, denominada de "MP da Liberdade Econômica", propondo supostamente menos burocracia nas relações empresariais para com o Estado, mas que na verdade, no que tange ao universo justrabalhista, incluindo os aspectos atinentes ao meio ambiente do trabalho, se revela em mais um reflexo do aludido momento de retrocesso socioambiental.

E referida conclusão se revela a partir do afrouxamento das normas atinentes aos estabelecimento de jornadas de trabalho, ampliando o poder do empregador na fixação destas, 
subjugando o trabalhador, já hipossuficiente, ao interesse empresarial, prejudicando aspectos relevantes do contrato de trabalho, dentre eles, o direito à saúde, segurança e integridade física, derivados da manutenção de um meio ambiente laboral saudável, equilibrado e justo, sob todos os aspectos.

Cumpre apontar que a Reforma Trabalhista serviu como "passaporte", ou seja, permissivo legal para o surgimento de outras disposições legislativas, de caráter precarizante e alijador, na medida em que reduz o alcance protetivo do meio ambiente do trabalho, ao excluir do seu próprio conceito, as disposições inerentes ao estabelecimento da duração do trabalho e seus intervalos, como se referidos elementos não estivessem vinculados e diretamente relacionados à saúde do trabalhador.

Os exemplos acima apontados, surgidos a partir da denominada Reforma Trabalhista e manifestados também a partir do surgimento da Medida Provisória n. ${ }^{\circ} 881$ de 2019, como a possibilidade de fracionamento das férias em três períodos, sendo um deles podendo se de cinco dias, redução de intervalo intrajornada para trinta minutos, estabelecimento de jornadas excessivas de trabalho desvinculadas das normas de saúde e segurança do trabalhador, banco de horas extenso (anual), facilitação da implantação da marcação de ponto por exceção, ampliação da não obrigatoriedade de controle formal de jornada para empresas com até vinte empregados, ao invés de dez, são aspectos que diminuem a amplitude, alcance e efeitos inerentes ao meio ambiente do trabalho.

E se tornam reflexos de um movimento de retrocesso, calcado em afrontas constitucionais flagrantes, rompendo com preceitos fundamentais e garantias à dignidade do ser humano, podendo gerar como notória consequência a impossibilidade de consecução do direito fundamental do trabalhador de obter a reposição de sua total condição de saúde física e mental, derivada do meio ambiente de trabalho digno e equilibrado.

Por conseguinte, revelam-se alcançados os objetivos propostos na pesquisa em questão, com a exposição de um contexto atual de inibição do meio ambiente do trabalho, em todos os seus aspectos, em total afronta aos comandos contidos na Constituição da República de 1988.

E uma preocupação aqui revelada deriva da conclusão de que referido momento atual, que teve como marco central a Lei 13.467 de 2017, tende a se perpetuar por tempo indeterminado, podendo surgir nos próximos anos novas medidas que afetam o meio ambiente 
laboral, as relações justrabalhistas e os direitos humanos.

A reflexão final é que a sociedade brasileira vivencia, atualmente, momentos delicados no que concerne às relações sociais, na medida em que a submissão a legislações decorrentes de retrocesso é uma tendência presente e futura, que poderá comprometer toda uma construção histórica de afirmação da relevância do meio ambiente em todos os seus aspectos. Inclusive, no que concerne à preservação e oferta do melhor ambiente de trabalho, no qual o homem se submete em grande parte do seu tempo diário e que, por isso, deveria ser objeto de máxima proteção e prestigio, ao contrário da referida tendência não protetiva que se pode vislumbrar, a partir de tudo o que aqui se expôs.

\section{REFERÊNCIAS BIBLIOGRÁFICAS}

BONAVIDES, Paulo. Curso de Direito Constitucional. 34. ed. Atual. São Paulo: Malheiros, 2019, 872p.

BRASIL. Constituição (1988). Constituição da República Federativa do Brasil. Brasília: Senado Federal, Centro Gráfico, 1988. Acesso em 26 set. 2017

BRASIL. Decreto Lei 5.452, de $1^{\circ}$ de Maio de 1943. Aprova a Consolidação das Leis do Trabalho. Disponível em < http://www.planalto.gov.br/ccivil_03/decreto-lei/Del5452.htm >. acessado em 26 set. 2017

BRASIL. Lei n. 13.467, de 13 de julho de 2017.

Altera a Consolidação das Leis do Trabalho (CLT), aprovada pelo Decreto-Lei no 5.452, de 10 de maio de 1943, e as Leis nos 6.019, de 3 de janeiro de 1974, 8.036, de 11 de maio de 1990, e 8.212, de 24 de julho de 1991, a fim de adequar a legislação às novas relações de trabalho.<http://www.planalto.gov.br/ccivil_03/_ato2015-2018/2017/lei/L13467.htm>. Acesso em 26 set. 2017.

CARDOSO. Ana Cláudia Moreira. Direito e dever à desconexão: disputas pelos tempos de trabalho e não trabalho. Revista UFMG, Belo Horizonte, v.23, nº 1 e 2, p. 62-85, 
jan./dez.2016. Disponível em:

<https://seer.ufmg.br/index.php/revistadaufmg/article/view/10992> Acesso em 28 mai. 2019.

CASSAR, Vólia Bomfim. Direito do Trabalho. 16. ed. Rio de Janeiro: Forense, 2018, 1372p.

DELGADO, Maurício Godinho. Curso de Direito do Trabalho. 17. ed. São Paulo: LTr, 2018, 1760p.

FELICIANO, Guilherme Guimarães; URIAS, João; MARANHÃO, Ney; SEVERO, Valdete Souto (Coord.). Direito Ambiental do Trabalho: Apontamentos para uma teoria geral. Vol.2. São Paulo: LTr, 2015, 581 p.

GARCIA, Bruna Pinotti. LAZARI, Rafael de. Manual de Direitos Humanos. Salvador: Jus Podium, 2014, 582p.

MARTINS, Thiago Penido. BRAZ, Virginía Lara Bernardes. As transformações nas relações de trabalho, a reforma trabalhista e a proibição ao retrocesso social. Revista Direito e

Desenvolvimento, João Pessoa, v. 9, n. 2, p. 95-117, ago./dez. 2018.

OLIVEIRA, Sebastião Geraldo. Proteção Jurídica à Saúde do Trabalhador. 4. ed. São Paulo: LTr, 2002, 526p.

PRATA, Marcelo Rodrigues. O Direito Ambiental do Trabalho Numa Perspectiva Sistêmica: As causas da inefetividade da proteção à ambiência laboral e o que podemos fazer para combate-la. São Paulo: LTr, 2013, 254p.

SANTOS, Adelson Silva dos. Fundamentos do Direito Ambiental do Trabalho. São Paulo: LTr, 2010, 176p.

SOUTO MAIOR, Jorge Luiz. Do direito à desconexão do trabalho. Revista do Tribunal Regional do Trabalho da 15. ${ }^{a}$ Região. Campinas, n. ${ }^{\circ} 23,2003$. Disponível em: <http://trt15.gov.br/escola_da_magistratura/Rev23Art17.pdf>. Acesso em 16 mai. 2019 